\title{
Utility of liver function tests in acute cholecystitis
}

\author{
Hady Zgheib ${ }^{1}$, Cynthia Wakil ${ }^{1}$, Sami Shayya ${ }^{1}$, Aurelie Mailhac ${ }^{2}$, \\ Muhyeddine Al-Taki ${ }^{3}$, Mazen El Sayed ${ }^{1,4}$, and Hani Tamim ${ }^{2,5}$ \\ ${ }^{1}$ Department of Emergency Medicine, ${ }^{2}$ Faculty of Medicine, Clinical Research Institute, \\ ${ }^{3}$ Division of Orthopedic Surgery, Department of Surgery, Faculty of Medicine, \\ ${ }^{4}$ Emergency Medical Services and Prehospital Care Program, ${ }^{5}$ Department of Internal Medicine, \\ American University of Beirut Medical Center, Beirut, Lebanon
}

\begin{abstract}
Backgrounds/Aims: Common bile duct stones (CBDS) affect the management of acute cholecystitis (AC). This study aims to investigate the utility of liver function tests (LFTs) in predicting the presence of CBDS in AC patients. Methods: Retrospective cohort study of adult patients with AC found in the American College of Surgeons National Surgical Quality Improvement Program database from 2008 to 2016. Patients were classified into two groups, without CBDS $\left(\mathrm{AC}^{-}\right)$and with CBDS $\left(\mathrm{AC}^{+}\right)$. LFT results namely total bilirubin, SGOT and ALP were collected and categorized into normal and abnormal with the cut-offs of $1.2 \mathrm{mg} / \mathrm{dl}$ for total bilirubin, $40 \mathrm{U} / \mathrm{L}$ for SGOT and $120 \mathrm{IU} / \mathrm{L}$ for ALP. Measures of diagnostic accuracy for individual and combinations of LFTs were computed. Results: A total of 32,839 patients were included in the study, with 8,801 (26.8\%) $\mathrm{AC}^{+}$and $24,038(73.2 \%) \mathrm{AC}^{-}$patients. Their mean age was $52.4( \pm 18.6)$ years and over half $(59.1 \%)$ were females. Mean LFT results were significantly higher in the $\mathrm{AC}^{+}$group for total bilirubin (1.82 vs 0.97$)$, SGOT (110.9 vs 53.3$)$ and ALP (164.4 vs 102.3$)(p<0.0001)$. The proportions of abnomal LFTs were significantly higher in the $\mathrm{AC}^{+}$group for total bilirubin (47.7\% vs $\left.20.2 \%\right)$, SGOT $(62.8 \%$ vs $27.1 \%$ ) and ALP (56.6\% vs $21.0 \%)(p<0.0001)$. Among $\mathrm{AC}^{+}$, the odds of having abnormal results for bilirubin, SGOT and ALP were found to be 3.61, 4.54 and 4.90 times higher than among $\mathrm{AC}^{-}$, respectively. Conclusions: Abnormal LFTs are strong predictors for the presence of CBDS in patients with AC. Normal LFTs should be interpreted with caution as some patients with $A C$ and CBDS might not present with characteristic abnormalities in results. (Ann Hepatobiliary Pancreat Surg 2019;23: 219-227)
\end{abstract}

Key Words: Acute cholecystitis; Common bile duct stone; Liver function test; Predictive value; Screening test

\section{INTRODUCTION}

Up to $7-20 \%$ of cases of acute cholecystitis (AC) are caused by a common bile duct stone (CBDS) ${ }^{1-3}$ The presence of a CBDS affects the management of AC in terms of timing and type of surgery. The diagnostic workup for a suspected AC case in the Emergency Department (ED), namely gallbladder ultrasounds and possibly abdominal CT scans are not highly sensitive or specific for detecting a CBDS. $^{4,5}$ Delays in definitive disposition and management (cholecystectomy) of patients with AC can result from additional workup such as magnetic resonance cholangio- pancreatography (MRCP) and/or endoscopic retrograde cholangiopancreatography (ERCP) which have high sensitivity and specificity for CBDS but are expensive, and not readily available in an ED setting.

Liver function tests (LFTs) levels in AC have been used to predict the presence of a CBDS. ${ }^{6,7}$ Patients with $\mathrm{AC}$ and $\mathrm{CBDS}\left(\mathrm{AC}^{+}\right)$or with $\mathrm{AC}$ without a $\mathrm{CBDS}(\mathrm{AC})$ can pathophysiologically have high LFTs. $^{8}$ While LFT elevation in $\mathrm{AC}^{+}$may be a direct effect of the obstructing CBDS, in patients with $\mathrm{AC}^{-}$, high $\mathrm{LFT}$ values may result from reactive hepatitis, portal tract inflammation, and direct pressure on biliary tract. ${ }^{9-12}$

Received: January 10, 2019; Revised: April 4, 2019; Accepted: April 20, 2019

Co-Corresponding author: Hani Tamim

Department of Internal Medicine, American University of Beirut Medical Center, Beirut 11072020, Lebanon

Tel: +961-1-350000 Ext: 6631, Fax: +961-1-350000 Ext: 5452, E-mail: htamim@aub.edu.lb

Co-Corresponding author: Mazen El Sayed

Department of Emergency Medicine, American University of Beirut Medical Center, P.O.Box - 11-0236 Riad El Solh, Beirut 11072020, Lebanon Tel: +961-1-350000 Ext: 6631, Fax: +961-1-350000 Ext: 6602, E-mail: melsayed@aub.edu.lb

Copyright (C) 2019 by The Korean Association of Hepato-Biliary-Pancreatic Surgery

This is an Open Access article distributed under the terms of the Creative Commons Attribution Non-Commercial License (http://creativecommons.org/ icenses/by-nc/4.0) which permits unrestricted non-commercial use, distribution, and reproduction in any medium, provided the original work is properly cited. Annals of Hepato-Biliary-Pancreatic Surgery • pISSN: 2508-5778 - elSSN: 2508-5859 
Abnormal LFTs are more common in $\mathrm{AC}^{+}$than in $\mathrm{AC}^{-6,8}$ Elevated LFTs were previously found to be significantly and independently associated with the presence of CBDS. ${ }^{13}$ Another study by Padda et al. ${ }^{8}$ found that the LFTs were all abnormal in $53 \%$ of $\mathrm{AC}^{+}$as compared to $18 \%$ of $\mathrm{AC}^{-}$ only, while all LFTs were normal in $35 \%$ of patients with $\mathrm{AC}^{-}$and $0.5 \%$ of $\mathrm{AC}^{+}$patients. Abnormal LFTs (including g-GT, alkaline phosphatase, ALT, and total bilirubin) were also previously identifed as strong predictors for CBDS. ${ }^{8,13}$

The utility of LFTs in predicting the presence of CBDS was however challenged by several other studies. One study reported that only $42 \%$ of the cases with elevated liver enzymes also had a CBDS. ${ }^{13}$ Many other studies found limited evidence for the link between LFTs and the presence of a CBDS. ${ }^{14-16}$ One study even suggested that none of the laboratory results were related to the presence of a CBDS. ${ }^{17}$ It is worth noting that even studies that found significant correlations between LFTs and the presence of a CBDS found relatively high numbers of false positive and false negative findings ${ }^{13}$ questioning their use as predictors for CBDS.

In this study, we aimed to describe characteristics of patients with confirmed acute cholecystitis and assess the utility of LFTs in predicting the presence of a CBDS in a large sample of patients from the American College of Surgeons National Surgical Quality Improvement Program (ACS NSQIP) database.

\section{MATERIALS AND METHODS}

\section{Setting and study population}

This is a retrospective cohort study of all adult patients with a diagnosis of AC found in the ACS NSQIP database between the years of 2008 and 2016. The ACS NSQIP is one of the first nationally validated programs obtaining risk-adjusted surgical outcomes for quality improvement purposes. The NSQIP database contains Health Insurance Portability and Accountability Act (HIPAA) de-identified data from over 600 participating hospitals. It includes comprehensive clinical data on more than 150 variables for patients undergoing surgical procedures, including patient demographics, preoperative risk factors, laboratory results and postoperative mortality and morbidity outcomes but excluding data on procedures performed on patients less than 18 years of age or those with an American Society of Anesthesiologists (ASA) score of 6, trauma cases, or cases referred to as "minor'. ${ }^{18}$ The ACS provides certified surgical clinical reviewers recording patient variables intensive training programs and continuous education in order to standardize data collection. They also conduct routine auditing to ensure data consistency and reliability. A systematic sampling strategy influenced by hospitals' surgical volume is adopted for a broad and diverse mixture of operative procedures to be captured.

An Institutional Review Board (IRB) exemption was obtained from the American University of Beirut to conduct this study using the HIPAA deidentified database.

The ACS NSQIP database was reviewed for all adult patients with a diagnosis of $\mathrm{AC}$ between the years of 2008 and 2016. AC cases were identified using International Classification of Disease (ICD) 9 and 10 diagnosis codes (Appendix 1).

Patients with active malignancy, whether they were known to have disseminated cancer or on radiotherapy for malignancy within the last 90 days or on chemotherapy for malignancy in less than 30 days were excluded from our study. We also excluded patients with missing data on all LFTs, as well as those with concomittant health conditions that might have affected LFT results such as patients on dialysis pre-operatively and patients with ascites, congestive heart failure or bleeding disorders. ${ }^{19}$

Patients were then classified into two groups, cases of $\mathrm{AC}^{-}$and $\mathrm{AC}^{+}$. ICD 9 and 10 codes were used to categorize the $\mathrm{AC}$ patients based on the presence or absence of CBDS (Appendix 1).

\section{Data collection}

Collected variables included demographic information (age, race, gender), comorbidites, ASA physical status classification class, body mass index (BMI), sepsis rates and pre-operative liver function tests available in the NSQIP database namely alkaline phosphatase (ALP), serum glutamic-oxaloacetic transaminase (SGOT) and total bilirubin. LFTs were measured using standard hospital laboratory techniques. Bilirubin was categorized as normal when $\leq 1.2 \mathrm{mg} / \mathrm{dl}$ and abnormal when $>1.2 \mathrm{mg} / \mathrm{dl}$. SGOT was categorized as normal when $\leq 40 \mathrm{U} / \mathrm{L}$ and abnormal when $>40 \mathrm{U} / \mathrm{L}$. ALP was categorized as normal when $\leq 120 \mathrm{IU} / \mathrm{L}$ and abnormal when $>120 \mathrm{IU} / \mathrm{L}$. 


\section{Data analysis}

A descriptive analysis among all patients and among $\mathrm{AC}^{+}$and $\mathrm{AC}^{-}$groups was carried out, with continuous variables presented as means \pm standard deviations and categorical variables presented as frequencies with percentages. This was followed by a bivariate analysis using Student's t-test and Pearson's Chi-square test to compare patients' characteristics between $\mathrm{AC}^{+}$and $\mathrm{AC}^{-}$groups.

The association between LFTs and the outcome of CBDS was assessed with LFTs considered individually and in combination. The LFT tests' results were first described and compared between patients with and without stone. Further analyses estimating sensitivities, specificities, positive predictive value, negative predictive value and diagnostic odds ratios (DORs) with their associated 95\% CI for each test and combinations of one, two or three LFTs were performed.

All statistical analyses were performed using SAS 9.4. Statistical significance was set at a bilateral $p$-value of 0.05 .

\section{RESULTS}

\section{Characteristics of $\mathrm{AC}$ patients}

A total of 32,839 patients were included in the study, among which 8,801 (26.8\%) were $\mathrm{AC}^{+}$and 24,038 (73.2\%) were $\mathrm{AC}^{-}$. Their mean age was $52.4 \pm 18.6$ years and over half $(59.1 \%)$ were of female gender. Patients were mostly white $(82.3 \%)$. Patients had a mean BMI of $30.9( \pm)$ (class I obesity) and over half (54.3\%) had a mild systemic disease (ASA class 2) followed by $32.5 \%$ with a severe systemic disease (ASA class 3).

Patients in the $\mathrm{AC}^{+}$group had slighly higer mean age ( $53 \pm 19.7$ years), were more commonly of female gender (64\%), and more likely to have an ASA score of 3 $(34.1 \%)(p<0.0001)$. They had lower mean white blood cell count (8.821 vs 10.577) $(p<0.0001)$, were less likely to have leukocytosis (WBC count of more than $11,000 / \mathrm{mm}^{3}$ ) $(22.29 \%$ vs $38.47 \%)$ and were less likely to be septic (17.2\% vs $21.4 \%, p<0.0001)$ (Table 1).

\section{Laboratory data}

Mean values for LFTs were significantly higher in the

Table 1. Demographics and characteristics of patients with cholecystitis with $\left(\mathrm{AC}^{+}\right)$or without $\left(\mathrm{AC}^{-}\right)$concomitant $\mathrm{CBDS}^{-}$

\begin{tabular}{|c|c|c|c|c|}
\hline Variables & All AC $(n=32839)$ & $\mathrm{AC}^{-}(\mathrm{n}=24038)$ & $\mathrm{AC}^{+}(\mathrm{n}=8801)$ & $p$-value \\
\hline Age (years), mean \pm SD & $52.4 \pm 18.6$ & $52.2 \pm 17.9$ & $53.0 \pm 19.7$ & 0.0006 \\
\hline Race & & & & $<0.0001$ \\
\hline Black & 3262 (11.6) & $2429(12.1)$ & $833(10.42)$ & \\
\hline White & $23052(82.3)$ & $16397(81.9)$ & $6655(83.23)$ & \\
\hline Others & $1710(6.1)$ & $1202(6.0)$ & $508(6.4)$ & \\
\hline \multicolumn{5}{|l|}{ Gender } \\
\hline Male & $13424(40.9)$ & $10259(42.7)$ & $3165(36.0)$ & $<0.0001$ \\
\hline Female & $19383(59.1)$ & $13755(57.3)$ & $5628(64.0)$ & \\
\hline Diabetic & 4538 (13.8) & 3447 (14.3) & $1091(12.4)$ & $<0.0001$ \\
\hline Hypertensive & $12551(38.2)$ & $9178(38.2)$ & $3373(38.3)$ & 0.8120 \\
\hline BMI, mean \pm SD & $30.9 \pm 7.5$ & $31.0 \pm 7.5$ & $31.1 \pm 7.6$ & 0.81 \\
\hline ASA & & & & 0.0010 \\
\hline 1 & $3245(9.9)$ & $2443(10.2)$ & $802(9.1)$ & \\
\hline 2 & $17803(54.3)$ & $13098(54.5)$ & $4705(53.5)$ & \\
\hline 3 & $10668(32.5)$ & $7672(32.0)$ & $2996(34.1)$ & \\
\hline 4 & $1078(3.3)$ & $787(3.3)$ & $291(3.3)$ & \\
\hline 5 & $9(0.0)$ & $8(0.0)$ & $1(0.0)$ & \\
\hline $\mathrm{WBC}$, mean $\pm \mathrm{SD}$ & $10.106 \pm 4.698$ & $10.577 \pm 4.797$ & $8.821 \pm 4.155$ & $<0.0001$ \\
\hline Hematocrit, mean \pm SD & $38.3 \pm 5.0$ & $38.6 \pm 5.0$ & $37.3 \pm 4.8$ & $<0.0001$ \\
\hline Septic & $6631(20.2)$ & $5122(21.4)$ & $1509(17.2)$ & $<0.0001$ \\
\hline
\end{tabular}

CBDS, common bile duct stone; $\mathrm{AC}$, acute cholecystitis; $\mathrm{AC}^{-}$, acute cholecystitis without common bile duct stone; $\mathrm{AC}^{+}$, acute cholecystitis with common bile duct stone; SD, standard deviation; BMI, body mass index; ASA, American Society of Anesthesiologists (ASA) Score is a global score that assesses the physical status of patients before surgery; WBC, white blood cell count 
$\mathrm{AC}^{+}$group for total bilirubin (1.82 vs $\left.0.97, p<0.0001\right)$, SGOT $(110.9$ vs 53.3, $p<0.0001)$ and ALP (164.4 vs 102.3, $p<0.0001$ ) (Table 2). The proportions of abnomal LFTs were also significantly higher in the $\mathrm{AC}^{+}$group for total bilirubin $(47.7 \%$ vs $20.2 \%, p<0.0001)$, SGOT $(62.8 \%$ vs $27.1 \%, p<0.0001)$ and ALP (56.6\% vs $21.0 \%, p<0.0001)$. When relying on two LFTs for the prediction of a CBD stone, the proportions of abnormal LFTs stayed significantly higher in the $\mathrm{AC}^{+}$group for all three combinations, with that of 'SGOT or ALP' having the highest rates of abnormal results $(73.8 \%$ vs $34.9 \%, p<0.0001)$ followed by 'total bilirubin or SGOT' (70.8\% vs 36.4\%, $p<0.0001)$ and 'total bilirubin or ALP' $(68.9 \%$ vs $32.8 \%$, $p<0.0001)$.

To assess the clinical utility of examining the three LFTs included in our study as binary variables for the prediction of CBDS in AC patients, ROC curves were constructed and the best cut-off points were determined using the Youden Index. Cut-off values were set at 1.2 milligrams per deciliter $(\mathrm{mg} / \mathrm{dl})$ for bilirubin, 40 units per liter
(U/L) for SGOT and 120 international units per liter (IU/L) for ALP. Sensitivities, specificities, positive and negative predictive values as well as diagnostic odds ratios for individual LFTs and combinations of LFTs are presented in Tables 3, 4, respectively. Among $\mathrm{AC}^{+}$, the odds of having abnormal results for bilirubin, SGOT and ALP were found to be 3.61, 4.54 and 4.90 times higher than among $\mathrm{AC}^{-}$, respectively (Table 3 ). $\mathrm{AC}$ patients with any abnormal LFT, any two abnormal LFTs and three abnormal LFts were found to be 2.23, 5.73 and 12.0 times more likely to have a simultaneous CBD stone, respectively (Table 4).

\section{DISCUSSION}

This study of more than 30,000 patients presenting with $\mathrm{AC}$ is the largest series to date to assess and characterize LFT results in $\mathrm{AC}^{+}$and $\mathrm{AC}^{-}$patients, with the purpose of developing clinically applicable criteria to assess the likelihood of a CBDS. The study findings confirmed the

Table 2. Liver function test results in acute cholecystitis patients with $\left(\mathrm{AC}^{+}\right)$or without $\left(\mathrm{AC}^{-}\right)$concomitant $\mathrm{CBDS}$

\begin{tabular}{|c|c|c|c|c|}
\hline LFTs & All AC & $\mathrm{AC}^{-}$ & $\mathrm{AC}^{+}$ & $p$-value \\
\hline Total bilirubin ${ }^{\mathrm{a}}$, mean $\pm \mathrm{SD}$ & $1.20 \pm 1.3$ & $0.97 \pm 1.01$ & $1.82 \pm 1.78$ & $<0.0001$ \\
\hline Normal $(\leq 1.2 \mathrm{mg} / \mathrm{dl})$ & $23798(72.5)$ & $19192(79.8)$ & $4606(52.3)$ & $<0.0001$ \\
\hline Abnormal $(>1.2 \mathrm{mg} / \mathrm{dl})$ & $9041(27.5)$ & $4846(20.2)$ & $4195(47.7)$ & \\
\hline $\mathrm{SGOT}^{\mathrm{a}}$, mean $\pm \mathrm{SD}$ & $68.7 \pm 105.9$ & $53.3 \pm 88.6$ & $110.9 \pm 134.0$ & $<0.0001$ \\
\hline Normal ( $\leq 40 \mathrm{U} / \mathrm{L})$ & $20802(63.3)$ & $17528(72.9)$ & $3274(37.2)$ & $<0.0001$ \\
\hline Abnormal $(>40 \mathrm{U} / \mathrm{L})$ & $12037(36.7)$ & $6510(27.1)$ & $5527(62.8)$ & \\
\hline $\mathrm{ALP}^{\mathrm{a}}$, mean $\pm \mathrm{SD}$ & $119.0 \pm 89.2$ & $102.3 \pm 72.0$ & $164.4 \pm 112.8$ & $<0.0001$ \\
\hline Normal $(\leq 120 \mathrm{IU} / \mathrm{L})$ & $22815(69.5)$ & $18993(79.0)$ & $3822(43.4)$ & $<0.0001$ \\
\hline Abnormal (>120 IU/L) & $10024(30.5)$ & $5045(21.0)$ & $4979(56.6)$ & \\
\hline \multicolumn{5}{|c|}{ Biliurubin OR SGOT, mean \pm SD } \\
\hline Normal & $17860(54.4)$ & $15290(63.6)$ & $2570(29.2)$ & $<0.0001$ \\
\hline Abnormal & $14979(45.6)$ & $8748(36.4)$ & $6231(70.8)$ & \\
\hline \multicolumn{5}{|l|}{ Bilirubin OR ALP, mean \pm SD } \\
\hline Normal & $18882(57.5)$ & $16147(67.2)$ & $2735(31.1)$ & $<0.0001$ \\
\hline Abnormal & $13957(42.5)$ & 7891 (32.8) & $6066(68.9)$ & \\
\hline \multicolumn{5}{|l|}{ SGOT OR ALP, mean \pm SD } \\
\hline Normal & $17960(54.7)$ & $15651(65.1)$ & $2309(26.2)$ & $<0.0001$ \\
\hline Abnormal & $14879(45.3)$ & $8387(34.9)$ & $6492(73.8)$ & \\
\hline \multicolumn{5}{|c|}{ SGOT OR ALP OR bilirubin, mean \pm SD } \\
\hline Normal & $15693(47.8)$ & $13761(57.2)$ & 1932 (21.9) & $<0.0001$ \\
\hline Abnormal & $17146(52.2)$ & $10277(42.8)$ & $6869(78.1)$ & \\
\hline
\end{tabular}

CBDS, common bile duct stone; LFTs, liver function tests; AC, acute cholecystitis; $\mathrm{AC}^{-}$, acute cholecystitis without common bile duct stone; $\mathrm{AC}^{+}$, acute cholecystitis with common bile duct stone; SD, standard deviation; SGOT, serum glutamic-oxaloacetic transaminase; ALP, alkaline phosphatase

${ }^{a}$ Cut-off values were set at 1.2 milligrams per deciliter (mg/dl) for bilirubin, 40 units per liter (U/L) for SGOT and 120 international units per liter (IU/L) for ALP 
Table 3. Test characteristics of individual LFTs for the prediction of CBDS in AC patients

\begin{tabular}{lccccc}
\hline & $\begin{array}{c}\text { Sensitivity, } \% \\
(95 \% \mathrm{CI})\end{array}$ & $\begin{array}{c}\text { Specificity, } \% \\
(95 \% \mathrm{CI})\end{array}$ & $\begin{array}{c}\text { PPV, } \% \\
(95 \% \mathrm{CI})\end{array}$ & $\begin{array}{c}\text { NPV, \% } \\
(95 \% \mathrm{CI})\end{array}$ & $\begin{array}{c}\text { Diagnostic OR } \\
(95 \% \mathrm{CI})\end{array}$ \\
\hline Bilirubin $^{\mathrm{a}}$ & $47.7(46.6-48.7)$ & $79.8(79.3-80.4)$ & $46.4(45.4-47.4)$ & $80.7(80.1-81.1)$ & $3.61(3.42-3.80)$ \\
SGOT $^{\mathrm{a}}$ & $62.8(61.8-63.8)$ & $72.9(72.4-73.5)$ & $45.9(45.0-46.8)$ & $84.3(83.8-84.8)$ & $4.54(4.32-4.79)$ \\
ALP $^{\mathrm{a}}$ & $56.6(55.5-57.6)$ & $79.0(78.5-79.5)$ & $49.7(48.7-50.7)$ & $83.3(82.8-83.7)$ & $4.90(4.65-5.17)$ \\
\hline
\end{tabular}

LFTs, liver function tests; CBDS, common bile duct stone; AC, acute cholecystitis; \%, percentage; PPV, positive predictive value; NPV, negative predictive value; Diagnostic OR, diagnostic odds ratio; CI, confidence interval; SGOT, serum glutamic-oxaloacetic transaminase; ALP, alkaline phosphatase

${ }^{a}$ Cut-off values were set at 1.2 milligrams per deciliter (mg/dl) for bilirubin, 40 units per liter (U/L) for SGOT and 120 international units per liter (IU/L) for ALP

Table 4. Test characteristics of combinations of LFTs for the prediction of CBDS in AC patients

\begin{tabular}{lccccc}
\hline & $\begin{array}{c}\text { Sensitivity, } \% \\
(95 \% \mathrm{CI})\end{array}$ & $\begin{array}{c}\text { Specificity, } \% \\
(95 \% \mathrm{CI})\end{array}$ & $\begin{array}{c}\text { PPV, \% } \\
(95 \% \mathrm{CI})\end{array}$ & $\begin{array}{c}\text { NPV, \% } \\
(95 \% \text { CI })\end{array}$ & $\begin{array}{c}\text { Diagnostic OR } \\
(95 \% \mathrm{CI})\end{array}$ \\
\hline Any one LFT $^{\mathrm{a}}$ & $48.5(46.9-50.1)$ & $70.3(69.7-71.0)$ & $23.9(22.9-24.8)$ & $87.7(87.2-88.2)$ & $2.23(2.08-2.39)$ \\
Any two LFTs $^{\mathrm{b}}$ & $54.0(52.5-55.5)$ & $83.0(82.4-83.6)$ & $44.6(43.2-46.0)$ & $87.7(87.2-88.2)$ & $5.73(5.33-6.17)$ \\
Three LFTs & $59.0(57.6-60.4)$ & $89.3(88.8-89.8)$ & $62.7(61.3-64.2)$ & $87.7(87.2-88.2)$ & $12.0(11.1-12.9)$ \\
\hline
\end{tabular}

LFTs, liver function tests; CBDS, common bile duct stone; AC, acute cholecystitis; \%, percentage; PPV, positive predictive value; NPV, negative predictive value; Diagnostic OR, diagnostic odds ratio; CI, confidence interval

${ }^{a}$ Any one LFT among total bilirubin, SGOT and ALP

${ }^{\mathrm{b}}$ Any two LFTs namely total bilirubin and SGOT, total bilirubin and ALP, and SGOT and ALP

usefulness of LFTs for the prediction of CBD stones in AC patients with mean LFT results being significantly greater in $\mathrm{AC}^{+}$patients than in $\mathrm{AC}^{-}$patients. This is in line with several previous studies that showed a significant increase in LFT results in AC patients with CBD stones. $^{6-8,13,20}$

Interestingly, $\mathrm{AC}^{+}$patients had lower mean WBC count (8.821 vs 10.577) $(p<0.0001)$, were less likely to have leukocytosis $(22.29 \%$ vs $38.47 \%$ ) and were less likely to be septic $(17.2 \%$ vs $21.4 \%, p<0.0001)$. Generally, in $\mathrm{AC}^{+}$patients, CBDS can cause cholangitis, which can present with high WBC count. ${ }^{21}$ The lower mean WBC count and proportion of patients with leukocytosis in $\mathrm{AC}^{+}$patients may be due to a baseline difference in severity of acute cholecystitis in $\mathrm{AC}^{+}$patients compared to $\mathrm{AC}^{-}$patients. Indeed, WBC count was shown to be significantly greater in patients with moderate rather than mild cholecystitis $^{22}$ or with gangrenous rather than non-gangrenous cholecystitis $(p \leq 0.04){ }^{23}$

As previously observed in the literature ${ }^{8,13,24}$ LFTs including total bilirubin, SGOT and ALP can vary in AC patients with or without CBDS. They are not only affected by the presence of CBDS but also by the severity and acuteness of $\mathrm{AC}^{25}$ Our study showed that both $\mathrm{AC}^{+}$and $\mathrm{AC}^{-}$patients could present with normal results. More than half of $\mathrm{AC}^{+}$patients had normal total bilirubin (52.3\%) and almost half had a normal ALP (43.4\%). Thus, findings of normal LFT should be interpreted with caution when ruling out CBDS.

There are several mechanisms may be responsible for the false negative and false positive LFTs in AC patients. In theory, $\mathrm{CBD}$ stones cause biliary obstruction with increased intra-biliary pressure due to hindrance of bile flow and subsequent peri-ductal inflammation and hepatocellular injury with elevated LFTs. ${ }^{8,10,25}$ However, partially obstructing stones may not cause elevated bilirubin levels thus generating false negative values. ${ }^{7,13}$ It is also possible for stones to spontaneously enter or pass from the CBD during the time period between blood sampling and surgery, thereby leading to both false negative or positive results, respectively. ${ }^{13}$ The presence of sludge or microlithiasis in the common bile duct could lead to an increased bile viscosity with subsequent elevation in liver function tests whereas they may go undetected on intraoperative cholangiography after they are washed out by the contrast medium to the duodenum, thus increasing the 
population of $\mathrm{AC}^{-}$patients with abnormal LFTs. ${ }^{26,27}$ Cases of concomitant Sphincter of Oddi dysfunction, ${ }^{28-31}$ conjugation defects $^{32,33}$ or Mirizzi syndrome ${ }^{34}$ among others may also display elevated liver function test results in the absence of CBDS.

Nevertheless, $\mathrm{AC}^{+}$patients are more likely to present with abnormal results. When compared to $\mathrm{AC}^{-}$patients, $\mathrm{AC}^{+}$patients tend to have more abnormal results with higher LFT values. As such, this study confirms the utility of LFTs for prediction of CBDS in AC patients to a certain extent, mainly for their positive predictive value in case of clinical suspicion. Of the LFTs assessed in this study, an abnormal ALP was the most powerful predictor for CBDS as it increased the odds of having concomitant CBDS by 4.9 fold. Abnormal SGOT and total bilirubin were also shown to be good predictors for CBDS with DORs of 4.54 and 3.61, respectively. A prospective study by Videhult et al. with 1171 cholecystitis patients established ALP and bilirubin as the most reliable factors, but with limited diagnostic value. ${ }^{13}$ Other studies have found different liver enzymes such as g-GT as more reliable predictors ${ }^{7}$ and Parra Pérez et al. ${ }^{17}$ concluded that none of the LFT results were associated with CBD stones. Many other studies targeting the use of LFTs for the prediction of CBDS only had limited results. ${ }^{14-16}$

Although ALP was found to have the most predictive power for a CBD stone, it is not advisable to order it solely as $56.6 \%$ of $\mathrm{AC}^{+}$cases would be missed. CBDS should be suspected if any of the predictors is elevated. ${ }^{13}$ Increasing the number of ordered LFTs substantially increased DORs for the prediction of a CBDS from 2.23 for any single LFT to 5.73 for any two LFTs up to 12.0 for all three LFTs (Table 4). Ordering the three LFTs together is advised for recognition of CBDS in AC patients.

For the diagnosis of CBDS, current practice relies on MRCP which is noninvasive or endoscopic ultrasound (EUS) which is less invasive than ERCP. EUS was found to have a sensitivity of $94 \%$ and a specificity of $95 \%$ in a meta-analysis on 27 studies with 2763 patients. ${ }^{35}$ MRCP was found to have a sensitivity of $93 \%$ and a specificity of $94 \%$ in a review of 13 studies. ${ }^{36}$ In our study, individual LFTs were found to have a sensitivity of 47.7 to $62.8 \%$ and specificity of 72.9 to $79.8 \%$. Although sensitivity and specificity of gold standard diagnostic procedures remain higher, prediction of CBD stone through ba- sic blood tests can be of great help before radiologic tests.

The limitations of our study are inherent to the use of a clinical registry database and include its retrospective study design as well as resource constraints such as missing data, miscoding and undocumented variables such as laboratory results namely direct bilirubin, ALT and G-GT or physical exam findings needed for severity grading of acute cholecystitis according to Tokyo guidelines. ${ }^{37}$ Relying on total bilirubin instead of conjugated or direct bilirubin is another limitation due to lack of differentiation between elevated levels from CBDS obstruction and those resulting from hemolysis or defective conjugation. ${ }^{13}$ Another limitation is related to the fixed cut-offs that were established to generate test characteristics for LFTs, which could be set higher to avoid false positive findings. Moreover, the ACS NSQIP database only contains data from participating hospitals, which do not constitute a statistically valid nationally representative sample. It only contains data on surgical patients with AC which might not be representative of all the $\mathrm{AC}$ patients who present to EDs. Only $0.1 \%$ of AC patients included in our study underwent ERCP and none of them underwent MRCP. This study however included a large number of confirmed cases of acute cholecystitis, and examined the utility of LFTs in a large national sample and its findings can be generalized to most ED settings with implications on daily clinical practice. Diagnostic odds ratios, which combine the strengths of sensitivity and specificity as prevalence independent indicators with the advantage of accuracy as signle indicator, were used as measures of test performance for the LFTs. Based on our findings, LFTs offer potential clinical benefits for diagnosis and treatment of CBD stones in $\mathrm{AC}$ patients. Not only would they help avoid unnecessary costs and complications associated with ERCP and MRCP in cases of normal results and low clinical suspicion for CBD stones but they also reduce the delay associated with these procedures making it possible to perform cholecystectomies more promptly.

A well designed prospective, large scale and multicenter study is still required in order to further evaluate the diagnostic value of LFTs for CBD stones in AC patients. Further areas of research include the study of LFT patterns in $\mathrm{AC}^{+}$and $\mathrm{AC}^{-}$patients after subgrouping based on the presence of concomitant chronic cholecystitis or acute pancreatitis ${ }^{13}$ as well as the study of the correlation 
between LFTs and morbidity/mortality outcomes.

Abnormal liver function tests are strong predictors for the presence of CBD stone in patients with acute cholecystitis, with ALP being stronger than SGOT and total bilirubin. This finding may help ED physicians better identify and predict which patients presenting with acute cholecystitis may also have a concomitant CBD stone and who may need additional inpatient work up, such as MRCP and ERCP to confirm CBDS presence. Normal LFTs should however always be interpreted with caution as some patients with acute cholecystitis and CBD stone might not present with characteristic abnormalities in results. A scoring system integrating LFTs and additional clinical variables would be useful to clinically help predict the presence of CBDS and avoid unnecessary delays related to additional work-up prior to definitive treatment.

\section{REFERENCES}

1. Mitchell SA, Jacyna MR, Chadwick S. Common bile duct stones: a controversy revisited. Br J Surg 1993;80:759-760.

2. Ko CW, Lee SP. Epidemiology and natural history of common bile duct stones and prediction of disease. Gastrointest Endosc 2002;56(6 Suppl):S165-S169.

3. Menezes N, Marson LP, debeaux AC, Muir IM, Auld CD. Prospective analysis of a scoring system to predict choledocholithiasis. Br J Surg 2000;87:1176-1181.

4. Baron RL. Common bile duct stones: reassessment of criteria for CT diagnosis. Radiology 1987;162:419-424.

5. Prat F, Meduri B, Ducot B, Chiche R, Salimbeni-Bartolini R, Pelletier G. Prediction of common bile duct stones by noninvasive tests. Ann Surg 1999;229:362-368.

6. Thapa PB, Maharjan DK, Suwal B, Byanjankar B, Singh DR. Serum gamma glutamyl transferase and alkaline phosphatase in acute cholecystitis. J Nepal Health Res Counc 2010;8:78-81.

7. Ahn KS, Yoon YS, Han HS, Cho JY. Use of liver function tests as first-line diagnostic tools for predicting common bile duct stones in acute cholecystitis patients. World J Surg 2016;40:19251931.

8. Padda MS, Singh S, Tang SJ, Rockey DC. Liver test patterns in patients with acute calculous cholecystitis and/or choledocholithiasis. Aliment Pharmacol Ther 2009;29:1011-1018.

9. Indar AA, Beckingham IJ. Acute cholecystitis. BMJ 2002;325: 639-643.

10. Geraghty JM, Goldin RD. Liver changes associated with cholecystitis. J Clin Pathol 1994;47:457-460.

11. Triger DR, MacIver AG, Gamlen TR, Wilken BJ. Liver abnormalities and gallstones: a prospective combined clinical, histological and surgical study. Br J Surg 1976;63:272-277.

12. Trowbridge RL, Rutkowski NK, Shojania KG. Does this patient have acute cholecystitis? JAMA 2003;289:80-86

13. Videhult P, Sandblom G, Rudberg C, Rasmussen IC. Are liver function tests, pancreatitis and cholecystitis predictors of common bile duct stones? Results of a prospective, population-based, cohort study of 1171 patients undergoing cholecystectomy. HPB
(Oxford) 2011;13:519-527.

14. Kaldor A, Akopian G, Recabaren J, Alexander M. Utility of liver function tests after laparoscopic cholecystectomy. Am Surg 2006;72:1238-1240.

15. Pereira-Limâ JC, Jakobs R, Busnello JV, Benz C, Blaya C, Riemann JF. The role of serum liver enzymes in the diagnosis of choledocholithiasis. Hepatogastroenterology 2000;47:1522-1525.

16. Zare M, Kargar S, Akhondi M, Mirshamsi MH. Role of liver function enzymes in diagnosis of choledocholithiasis in biliary colic patients. Acta Med Iran 2011;49:663-666.

17. Parra Pérez V, Vargas Cárdenas G, Astete Benavides M, Valdivia Roldán M, Morán Tisoc L, Nuñez Calixto N, et al. [Choledocolithiasis predictors in high-risk population subjected to endoscopic retrograde pancreatocholangiography at "Hospital Nacional Arzobispo Loayza”]. Rev Gastroenterol Peru 2007;27:161-171. Spanish.

18. American College of Surgeons. ACS National Surgical Quality Improvement Program. Chicago: American College of Surgeons, 2011.

19. Johnston DE. Special considerations in interpreting liver function tests. Am Fam Physician 1999;59:2223-2230.

20. Song SH, Kwon CI, Jin SM, Park HJ, Chung CW, Kwon SW, et al. Clinical characteristics of acute cholecystitis with elevated liver enzymes not associated with choledocholithiasis. Eur J Gastroenterol Hepatol 2014;26:452-457.

21. Ahmed M. Acute cholangitis - an update. World J Gastrointest Pathophysiol 2018;9:1-7.

22. Er S, Ozden S, Celik C, Yuksel BC. Can we predict severity of acute cholecystitis at admission? Pak J Med Sci 2018;34:12931296.

23. Teefey SA, Dahiya N, Middleton WD, Bajaj S, Dahiya N, Ylagan L, et al. Acute cholecystitis: do sonographic findings and WBC count predict gangrenous changes? AJR Am J Roentgenol 2013; 200:363-369.

24. Habib L, Mirza MR, Ali Channa M, Wasty WH. Role of liver function tests in symptomatic cholelithiasis. J Ayub Med Coll Abbottabad 2009;21:117-119.

25. Fikry AA, Kassem AA, Shahin D, Shabana H. Elevated liver enzymes in patients with cholecystitis. J Surg 2014;2:38-41.

26. Kelly DA. Intestinal failure-associated liver disease: what do we know today? Gastroenterology 2006;130(2 Suppl 1):S70-S77.

27. Thorbøll J, Vilmann P, Jacobsen B, Hassan H. Endoscopic ultrasonography in detection of cholelithiasis in patients with biliary pain and negative transabdominal ultrasonography. Scand J Gastroenterol 2004;39:267-269.

28. Elta GH. Sphincter of Oddi dysfunction and bile duct microlithiasis in acute idiopathic pancreatitis. World J Gastroenterol 2008;14:1023-1026.

29. Petersen BT. Sphincter of Oddi dysfunction, part 2: evidencebased review of the presentations, with "objective" pancreatic findings (types I and II) and of presumptive type III. Gastrointest Endosc 2004;59:670-687.

30. Petersen BT. An evidence-based review of sphincter of Oddi dysfunction: part I, presentations with "objective" biliary findings (types I and II). Gastrointest Endosc 2004;59:525-534.

31. McLoughlin MT, Mitchell RM. Sphincter of Oddi dysfunction and pancreatitis. World J Gastroenterol 2007;13:6333-6343.

32. Bosma PJ. Inherited disorders of bilirubin metabolism. J Hepatol 2003;38:107-117.

33. Radu P, Atsmon J. Gilbert's syndrome--clinical and pharmacological implications. Isr Med Assoc J 2001;3:593-598.

34. Beltrán MA. Mirizzi syndrome: history, current knowledge and proposal of a simplified classification. World J Gastroenterol 2012;18:4639-4650. 
35. Tse F, Liu L, Barkun AN, Armstrong D, Moayyedi P. EUS: a meta-analysis of test performance in suspected choledocholithiasis. Gastrointest Endosc 2008;67:235-244.

36. Kaltenthaler E, Vergel YB, Chilcott J, Thomas S, Blakeborough $\mathrm{T}$, Walters SJ, et al. A systematic review and economic evaluation of magnetic resonance cholangiopancreatography compared with diagnostic endoscopic retrograde cholangiopancreatography. Health Technol Assess 2004;8:iii, 1-89.

37. Yokoe M, Hata J, Takada T, Strasberg SM, Asbun HJ, Wakabayashi G, et al. Tokyo Guidelines 2018: diagnostic criteria and severity grading of acute cholecystitis (with videos). J Hepatobiliary Pancreat Sci 2018;25:41-54. 
Appendix 1. ICD9 and ICD10 codes used to categorize the acute cholecystitis (AC) patients based on the absence or presence of common bile duct stones into $\mathrm{AC}^{-}$and $\mathrm{AC}^{+}$cases

\begin{tabular}{llllllllll}
\hline ICD9 & 574.30 & 574.31 & 574.60 & 574.61 & 574.80 & 574.81 & 575.0 & 575.12 & 574.01 \\
ICD10 & K80.42 & K80.43 & K80.62 & K80.63 & K80.66 & K80.67 & K81.0 & K81.2 & K80.01 \\
\hline
\end{tabular}

\begin{tabular}{|c|c|c|c|c|c|c|c|}
\hline \multicolumn{4}{|c|}{$\mathrm{AC}^{+}$} & \multicolumn{4}{|c|}{$\mathrm{AC}^{-}$} \\
\hline ICD9 & Label & ICD10 & Label & ICD9 & Label & ICD10 & Label \\
\hline 574.30 & $\begin{array}{l}\text { Calculus of bile } \\
\text { duct with acute } \\
\text { cholecystitis, } \\
\text { without mention } \\
\text { of obstruction }\end{array}$ & K80.42 & $\begin{array}{l}\text { Calculus of bile } \\
\text { duct with acute } \\
\text { cholecystitis without } \\
\text { obstruction }\end{array}$ & 575.0 & $\begin{array}{l}\text { All types of acute } \\
\text { cholecystitis, no } \\
\text { stones, no chronic } \\
\text { cholecystitis }\end{array}$ & K81.0 & Acute cholecystitis \\
\hline 574.31 & $\begin{array}{l}\text { Calculus of bile } \\
\text { duct with acute } \\
\text { cholecystitis, } \\
\text { with obstruction }\end{array}$ & K80.43 & $\begin{array}{l}\text { Calculus of bile } \\
\text { duct with acute } \\
\text { cholecystitis, with } \\
\text { obstruction }\end{array}$ & 575.12 & $\begin{array}{l}\text { Acute and chronic } \\
\text { cholecystitis, no } \\
\text { stones }\end{array}$ & K81.2 & $\begin{array}{l}\text { Acute cholecystitis } \\
\text { with chronic } \\
\text { cholecystitis }\end{array}$ \\
\hline 574.60 & $\begin{array}{l}\text { Calculus of } \\
\text { gallbladder and } \\
\text { bile duct with } \\
\text { acute cholecystitis, } \\
\text { without mention } \\
\text { of obstruction }\end{array}$ & K80.62 & $\begin{array}{l}\text { Calculus of } \\
\text { gallbladder and } \\
\text { bile dut with acute } \\
\text { cholecystitis without } \\
\text { obstruction }\end{array}$ & 574.01 & $\begin{array}{l}\text { Calculus of } \\
\text { gallbladder with } \\
\text { acute cholecystitis, } \\
\text { with obstruction }\end{array}$ & K80.01 & $\begin{array}{l}\text { Calculus of } \\
\text { gallbladder with } \\
\text { acute } \\
\text { cholecystitis, } \\
\text { with obstruction }\end{array}$ \\
\hline 574.61 & $\begin{array}{l}\text { Calculus of } \\
\text { gallbladder and } \\
\text { bile duct with } \\
\text { acute cholecystitis, } \\
\text { with obstruction }\end{array}$ & K80.63 & $\begin{array}{l}\text { Calculus of } \\
\text { gallbladder and bile } \\
\text { duct with acute } \\
\text { cholecystitis, with } \\
\text { obstruction }\end{array}$ & - & - & - & - \\
\hline 574.80 & $\begin{array}{l}\text { Calculus of } \\
\text { gallbladder and bile } \\
\text { duct with acute and } \\
\text { chronic cholecystitis, } \\
\text { without mention of } \\
\text { obstruction }\end{array}$ & K80.66 & $\begin{array}{l}\text { Calculus of } \\
\text { gallbladder and bile } \\
\text { duct with acute and } \\
\text { chronic cholecystitis, } \\
\text { without obstruction }\end{array}$ & - & - & - & - \\
\hline 574.81 & $\begin{array}{l}\text { Calculus of } \\
\text { gallbladder and bile } \\
\text { duct with acute and } \\
\text { chronic cholecystitis, } \\
\text { with obstruction }\end{array}$ & K80.67 & $\begin{array}{l}\text { Calculus of } \\
\text { gallbladder and bile } \\
\text { duct with acute and } \\
\text { chronic cholecystitis, } \\
\text { with obstruction }\end{array}$ & - & - & - & - \\
\hline
\end{tabular}

